\title{
Best Practices in Track Two Diplomacy
}

\author{
Peter Jones ${ }^{1}$ \\ Graduate School of Public and International Affairs, and Ottawa Dialogue, \\ University of Ottawa, 120 rue Université, Rm Fss-6058, Ottawa, Ontario, \\ $\mathrm{K}_{1} \mathrm{~N}_{5}$, Canada \\ Peter.Jones@uOttawa.ca
}

Received 21 December 2019; accepted 10 June 2020

\begin{abstract}
While "Track Two Diplomacy" has been intensively researched since its founding some 6 o years ago, much remains to be done to explore important gaps in our understanding of these dialogues. Track Two presents unusual research problems, given its operational and often confidential nature. The contributions to this special issue of International Negotiation tackle some of the key issues confronting the field in an effort to present where we stand in terms of best practices and where further thought and research is required.
\end{abstract}

\section{Keywords}

Track Two Diplomacy - Multi-Track Diplomacy - Track 1.5 - controlled communication - conflict management - conflict resolution - conflict transformation

It has been six decades since John Burton and his colleagues first convened unofficial workshops on conflicts in South East Asia and developed the concept of "controlled communication" to describe their work. It has been almost four

1 Peter Jones is an Associate Professor in the Graduate School of Public and International Affairs at the University of Ottawa. He is also the Executive Director of the Ottawa Dialogue, an organization based at the University which runs Track 1.5 and Track 2 dialogues around the world. He is the author of Track Two Diplomacy: In Theory and Practice (Stanford University Press 2015) 
decades since Joseph Montville first coined the term "Track Two Diplomacy" to describe these kinds of informal and unofficial, problem-solving workshops. ${ }^{2}$ In that time, much has been written about the many aspects of this field and we understand more deeply many aspects of these interactions. But questions remain and our grasp of the phenomenon continues to evolve.

The contributions to this special thematic issue of International Negotiation arose from a panel discussion at the 2017 International Studies Association (ISA) conference in Baltimore on "Best Practices in Track Two Diplomacy." These articles have been extensively developed since then and other authors have been brought into the process to cover issues not addressed in Baltimore. The objective of that panel, and of this thematic issue, remains to describe and analyze the best practices which have emerged to date regarding issues that dominate the field and to suggest areas where further research is required.

Track Two is an unusual field for the social sciences. It is inherently crossdisciplinary, defying easy categorization even as it seeks a place for itself within academe as a scholarly and rigorous discipline. It is very much a field where theory informs practice, and practice informs theory, but each case is so specific as to make wide-ranging theoretical rules difficult to apply beyond a certain level of generality. Its practitioners are also often scholars seeking to develop the field academically as they go about their practice, but mindful of the fact that their work often means that the standard conventions of academe must be modified (for instance, on such matters as confidentiality versus openness). It seeks to influence official diplomacy, even as it jealously guards its independence from it. Some forms of Track Two eschew relations with officialdom altogether.

Given all of this, it is not surprising that a collection of research such as presented here would feature different approaches and conceptions in some respects. However, by focusing each article on the theme of best practices, we hope that they each complement and strengthen each other. One way of characterizing the articles is that they move from what might be called the specific to the general. By this it is meant that the initial papers tackle rather specific and discrete issues confronting the field, while the later ones raise broader questions about how the field views itself and its objectives.

The article by Tamra Pearson d'Estrée and Benjamin B. Fox considers the critical issue of how the results of a Track Two project are transferred to the intended audience. It looks at how thinking in the field has significantly evolved over the decades, before identifying and analyzing the best practices which

2 For more on the history of the field see Fisher (2002); Mitchell (2001); Jones (2015: chapter 1). 
have emerged from this experience. Their article develops a checklist of key issues pertaining to transfer which has arisen from practice over many decades. This checklist will be a boon to those active in the field in their attempts to improve practice and also to those who seek to understand it better.

Peter Jones explores the question of the ethics of Track Two, seeking to identify best practices in this area. While most practitioners in the field see their work as intrinsically ethical and moral, Jones notes that there are some key ethical issues which need to be considered by those who would insert themselves into conflict situations, especially those from the outside. He concludes that the field, as a whole, needs to devote more reflection and effort to these questions and to establish a mechanism whereby practitioners can reach out to each other for assistance and advice in dealing with their ethical conundrums.

Susan Allen explores best practices around the issue of the local ownership of Track Two interventions, as opposed to reliance on outside intervenors to facilitate such interactions. While a bias has developed over the years in the literature in favor of local ownership of dialogues as an intrinsic good, one which Allen supports on the whole, she finds that it is not so simple in practice. Each approach has its benefits and drawbacks. Drawing on her own extensive experience of facilitating such dialogues, especially in the Caucasus region, Allen proposes a model which builds on the strengths of each through cooperation and evolution over time.

Elizabeth Shillings and Peter Jones propose a model to tackle one of the most vexing questions in the field: how to measure or evaluate the impact of a Track Two dialogue. Their model provides a framework which encourages those interested in making such an evaluation to reflect upon the key questions and input their responses on a chart that provides a visual reference point as to how much and what kind of an impact their work had. Key to the proper use of the model is the understanding that it is not meant to provide hard and fast answers, as such are likely not available given the imprecise nature of the issue. Rather, the model is a tool to encourage much greater reflection on the part of practitioners and others as to how the intervention affected the situation, both at the time and over time.

Esra Çuhadar carefully unpacks the cognitive frames that Track Two practitioners bring to their interventions, often unconsciously. These frames bias practitioners towards certain types of interventions and methodologies. Relying on extensive interviews with a wide range of practitioners, Çuhadar identifies the most common cognitive frames adopted by practitioners and subjects each to rigorous analysis to determine which types of conflicts they are best suited for and why. 
Finally, Philip Gamaghelyan steps back and seeks to address the debate in the field over whether such interventions should try to manage, resolve, or transform conflicts. Though this is not a new debate, his discussion of its development is both illuminating and thoughtful. Gamaghelyan, drawing on his own experience as a practitioner, has much to say about the often unspoken assumptions which underpin the conflict management and resolution approaches and firmly argues in favor of greater attention to, and development of, the transformation agenda. Even here, however, he is cognizant that best practice leaves much to be desired and requires further thought and development.

Bringing these papers from their initial drafts to the product you see before you has been a longer, and more circuitous process than any of us anticipated. Some of this is down to the usual propensity of academics to take longer than promised to actually write (and I am the most guilty party here). But I believe that much of the time required has had to do with the fact that each author took it upon themselves to deeply examine and question foundational issues in the field. This is not easy and sometimes not comfortable.

Taken together, these articles present a fulsome overview and analysis of the state of Track Two diplomacy on a number of the key issues that it faces. The contributions tend to argue that the field requires much more by way of ongoing self-reflection on these matters. For all that has been done to develop the field over the six decades since 'controlled communication' made its appearance, much remains to be discovered. In a short paper at the conclusion of this issue I will summarize our findings and address the question of what needs to be done to further the development of best practices in the field of Track Two.

\section{References}

Fisher, R.J. (2002). "Historical Mapping of the Field of Inter-active Conflict Resolution," in J. Davies and E. Kaufman, editors, Second Track/Citizen's Diplomacy: Concepts and Techniques for Conflict Transformation. Lanham, MD: Rowman \& Littlefield. Jones, P. (2015). Track Two Diplomacy in Theory and Practice. Palo Alto CA: Stanford University Press.

Mitchell, C.R. (2001). "From Controlled Communication to Problem Solving: The Origins of Facilitated Conflict Resolution." The International Journal of Peace Studies 6, 1. At: https://www.gmu.edu/programs/icar/ijps/vol6_1/Mitchell2.htm. 